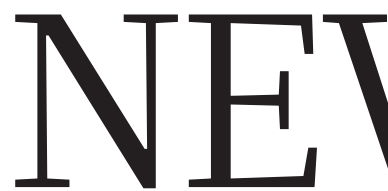

NATURAL DISASTERS Landslide prediction system debuts at world forum $\mathbf{p . 2 7 2}$
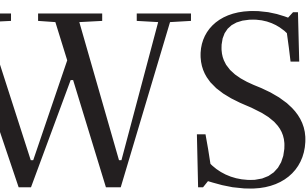
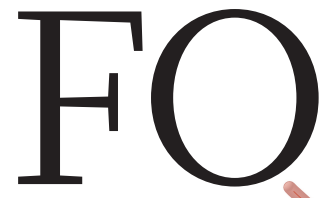
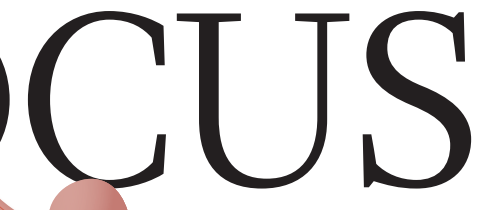

FUNDING Scripps merger failure highlights plight of private research institutes $\mathbf{p . 2 7 4}$
FUNDING CERN charity launch seeks donations for big physics $\mathbf{p . 2 7 6}$
WEIGHT LOSS How gastric

surgery causes

metabolic changes p.282

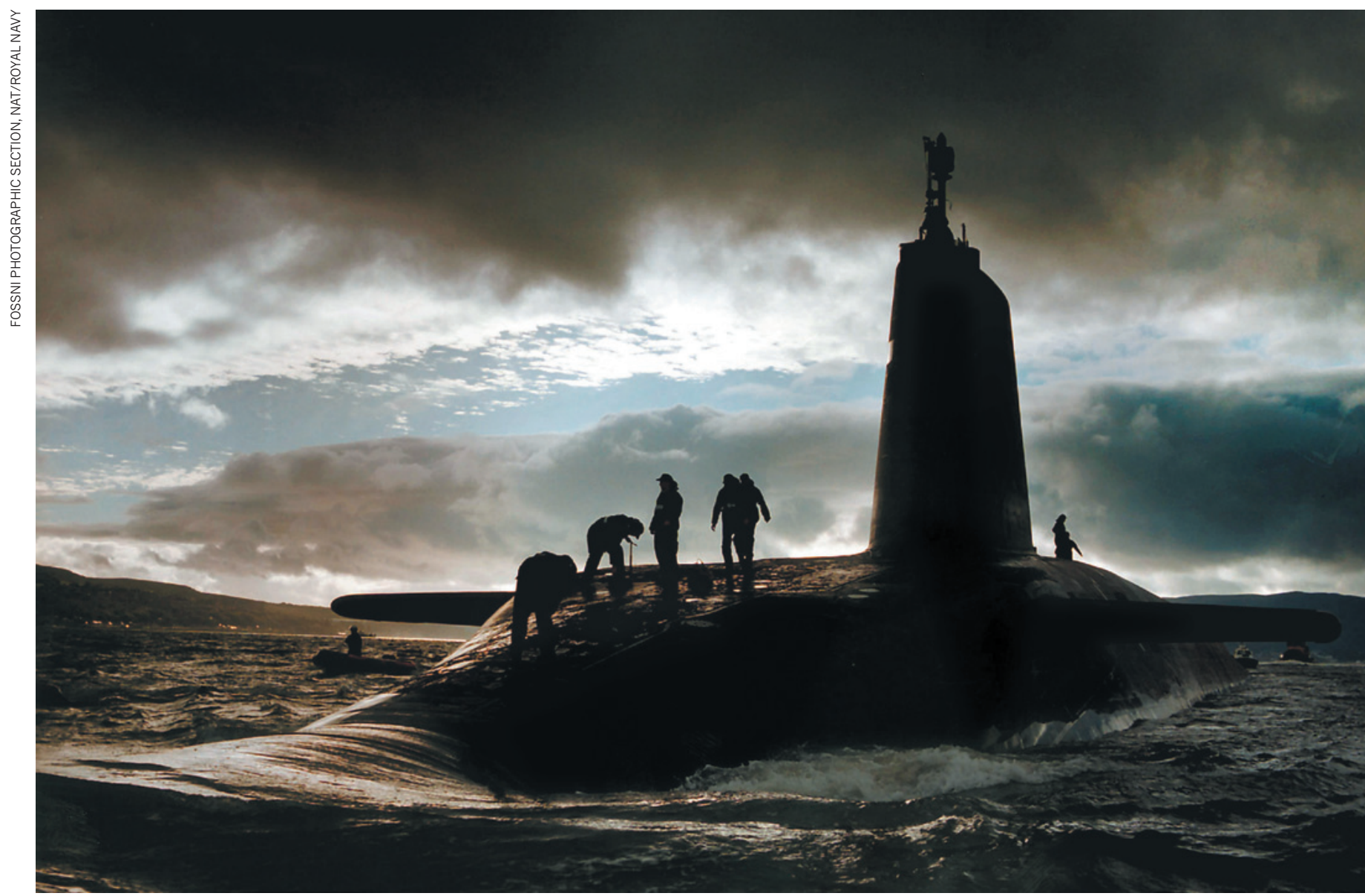

The Royal Navy's nuclear submarines could benefit from a navigation system based on quantum technology now under development.

\title{
Quantum-hub finalists picked
}

\section{UK government considers eight proposals for up to six research centres.}

\section{BY KATIA MOSKVITCH}

The UK government has narrowed the list of teams competing for millions of 1 pounds in quantum-technology funding down to the last eight. Pledged in December by UK chancellor George Osborne, the $£ 270$-million (US $\$ 462$-million) funding pot is primarily meant to establish up to six research hubs focusing on different applications of the rapidly advancing field.

The teams still in the running - led by
Imperial College London, University College London and the universities of Birmingham, Bristol, Glasgow, Lancaster, Oxford and York - will learn on 15 September whether their proposals have been accepted by the National Quantum Technologies Programme. "I think this is the biggest single investment in the emerging technologies that the UK government has ever made," says Peter Knight, a physicist at Imperial College and former president of the Institute of Physics in London.

For decades, quantum physics seemed too esoteric to have much practical use. But now, physicists see opportunities to take quantum research out of the lab and into real life. Technologies that harness the peculiar qualities of quantum mechanics seem poised to deliver breakthroughs in a wide range of applications.

"The pace of transition from theoretical concepts to realizable quantum technologies is astonishing," says Nicola Wilkin, a theoretical physicist at the University of Birmingham. "Applications that will be rapidly realized 
- include unprecedented gravitational sensors to find oil and minerals, clocks that deliver next-generation navigation, and secure broadband communication."

Of the $£ 270$ million, $£ 190$ million is new money; the rest will be drawn from the government's roughly $£ 1$-billion annual allocation for science capital funding. Most of the money will be distributed through the Engineering and Physical Sciences Research Council (EPSRC).

"Each hub will cover a carefully selected theme, such as computing or communication, where quantum technologies can provide game-changing advances and benefit from enhanced collaboration between industry, academia and government," thenscience minister David Willetts told Nature.

Imperial College proposes a hub focused on manipulating the quantum states of ultracold atoms. An Imperial project already under way with funding from the UK Defence Science and Technology Laboratory aims to develop a quantum-based ultra-precise submarine positioning system for the Royal Navy. Submarines face a navigation challenge because they cannot contact positioning satellites without surfacing. "After six months of wandering around under the ocean, you could be way off where you think you are," says Imperial physicist and project leader Edward Hinds. The system promises to be 1,000 times more accurate than today's technology - with no need to surface. And because space is at a premium on submarines, the researchers also want to make the device smaller; their current model is 50 centimetres wide. The team hopes to have a narrower prototype available by 2016 .

Other teams are focusing on different applications. The Lancaster University group, for example, aims to develop quantum sensors and metrology tools for use in health care and nuclear power, says Yuri Pashkin, director of Lancaster's Quantum Technology Centre, which opened in May. And University of Oxford physicist Ian Walmsley says that his institution's proposed hub would establish Britain as a global leader in quantum technologies for defence, communications, pharmaceuticals and finance by pursuing powerful computers, simulators, communications networks and sensors.

The goal of the investment is to secure the United Kingdom's strong global position in quantum physics and keep British quantum physicists at home, says Rachel Bishop, theme leader for quantum technologies at the EPSRC in Swindon. "As a scientist, you want to work somewhere exciting where you can explore your ideas in a well-funded research environment and that's exactly what the government is doing in quantum."

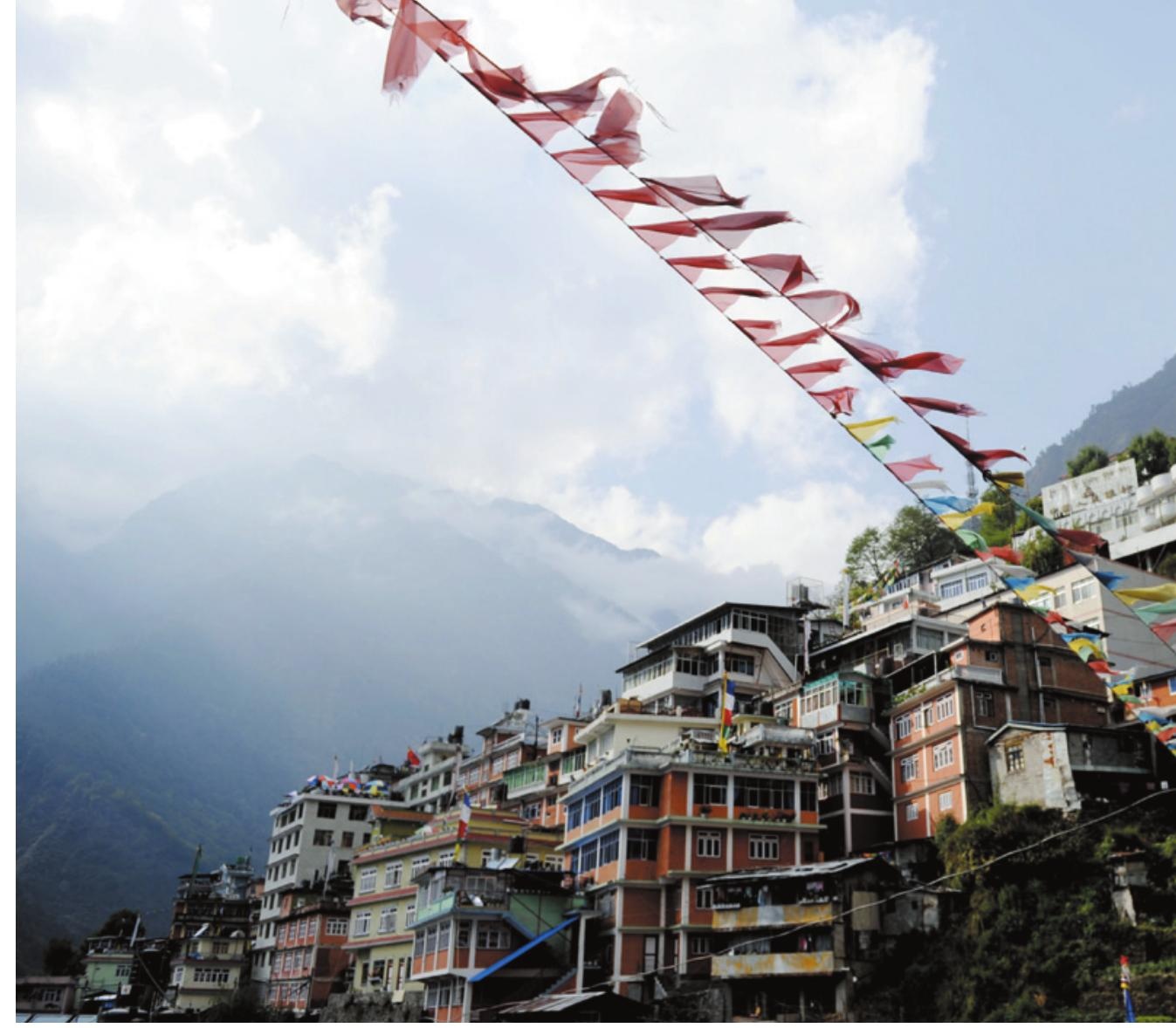

Plans are afoot to improve landslide monitoring for the endangered town of Zhangmu in Tibet.

\section{NATURAL HAZARDS}

\section{Landslide risks rise up agenda}

\section{Forum on deadly natural phenomena discusses use of simulation and hazard-mapping technologies.}

\section{BY JANE QIU}

$\mathrm{T}$ The Tibetan town of Zhangmu is on edge - in an emotional and physical sense. Perched precariously on a mountainside, the growing trading and tourist centre lives under the constant threat of landslides, the result of a formidable combination of geological, climatic and developmental factors. The settlement, whose population reaches 40,000 in summer months, is built on the unstable debris of past landslides. As more buildings appear, the risk of a catastrophic collapse increases.

Many settlements across the globe face a similar predicament. With extreme weather events becoming more common, land resources dwindling and urban development spiralling, landslides "are increasing in frequency, scope and destructive capacity”, says Sálvano Briceño, chair of the scientific committee at Integrated Research on Disaster Risk, an international research programme headquartered in Beijing.
But the risks are being addressed. At the third World Landslide Forum in Beijing last month, researchers met to discuss ways to improve the monitoring, prevention and management of these lethal phenomena. Presentations included technologies for mapping hazards and providing early warnings, as well as computer models that simulate the effects of rainwater and earthquakes. "With the projected increase in extreme rainfall, communities in landslideprone regions will be more vulnerable," said Rex Baum, a geologist with the US Geological Survey in Golden, Colorado.

Slope failures are the biggest landslide threat. These occur when a chunk of slope becomes detached from a hillside. As the material descends, shearing forces increase the pressure of water in the gaps between soil and rock particles (the pore-water pressure), causing clumps of slope materials to collapse. This process, called liquefaction, can be a result of rainfallinduced increases in water volume or seismic 